\title{
Research on the Emotional Expression and Innovation of Digital Technology under Visual Communication-Taking the fight "epidemic" image as an example
}

\author{
Jiani $\mathrm{Liu}^{1}$ \\ ${ }^{1}$ Hunan Normal University Fine Arts Academy, Changsha, Hunan, China
}

\begin{abstract}
The unexpected outbreak of the Covid-19 in 2020 has shifted the focus of the media worldwide to the comprehensive, tridimensional and truthful coverage of the catastrophe to the audience. Through the shooting of the Wuhan epidemic as an example, the article analyzes the photographic works in the epidemic, and discusses the innovation of images under the visual communication of digital technology, so that the fight "epidemic" images have become historical witnesses and development tracks.
\end{abstract}

\section{Introduction}

From the sociological point of view, documentary photography involves a behavior of delivering documentary visual images by the photographer with an aim to consciously reveal people's state of existence in the natural environment. This behavior entails photographic subjects with certain historical and documentary value to record human's role in natural activities. documentary photography in disasters is a unique way to reflect the disasters

Thus, documentary photographers would pay more attention to the society and human nature, go deep into the cultural deposits, and respect customs and habits. Here is the discussion of the spread value of documentary photography of "wars and epidemics" combined with the COVID-19 outbreak in China.

\section{Necessity of Documentary Photography of Epidemics in the Context of Visual Communication}

In general, visual communication is summarized into four elements: "who", "what", "to whom" and "effects and influences". In daily life, visual communication can be seen everywhere such as television, film, architecture and plastic arts.

"Photography is a basic principle and, most importantly, a standard of observation," said Sontag, a famous photographer and critic. Photography has become the only "language" that can be understood all over the world. Documentary photography in disasters is a very unique way to reflect the disasters. In the context of COVID-19 outbreak, especially in Wuhan, the most affected city, people can intuitively understand and feel the suffering brought about by the pandemic through the photos. And to a certain extent, these photos can also affect the process "fighting the virus" and help deal with the difficulties and problems in the affected areas.

Disasters themselves are characterized by the nature of suddenness. In January 2020, the COVID-19, which could have been controlled, caused a nationwide increase of confirmed cases because of the false reports that "the virus is preventable and controllable". When searching for "COVID-19" on the Internet, plenty of relevant news and photographs will emerge.

In this circumstance, due to the fierce conflict of fate, personality, religion, ideology and other reasons, humans have suffered from undue hardships and the goodness of humanity has been destroy. In the face of suffering and pains, people first have fear and compassion, vent and purify their feelings, and then pursue an inspiring noble spirit.

During the period of COVID-19, the major news media splashed the epidemic and the stories related to it. In terms of the image representation of doctors, nurses and volunteers who were fighting in the front line of the epidemic, the function and advantages of photography were fully exerted. Under the premise of reflecting the real situation, the firsthand photos shocked people's vision and conveyed information to them.

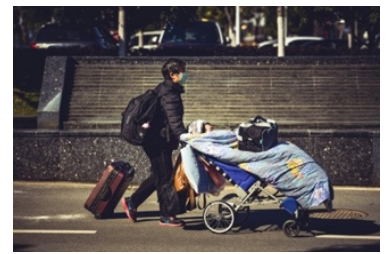

(Figure 1 Resurrection)

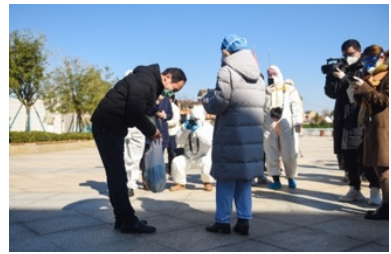

(Figure 2 Bowing)
Resurrection (Figure 1) was taken on February 17, 2020 in Wuhan Sino-French Eco-City branch of Tongji Hospital. That day is the 25th of Wuhan's lockdown since 
the COVID-19 outbreak. Even though the number of confirmed cases of the COVID-19 was on the rise, the patients who had been cured were discharged successfully. There were moving scenes where some kidney-transplant recipients who were diagnosed with the COVID-19 bowed to their doctors to express their gratitude after they were cured of the COVID-19 (Figure 2). According to the doctor on the spot, the virus is not scary and where there is confidence there is a way. Bathing in the new life, people can see the power of "fighting the epidemic".

In face of the COVID-19 outbreak, documentary news photography has been proved to be the most acceptable means for the audience to transmit the information on the scene of "fighting the epidemic". Press photographers and freelance photographers take cameras, paper and pens as their weapons to form a strong force and reach out to the people in trouble. Then they upload what the people are suffering to the media or the Internet. Such a way of reporting and publicizing has a substantial role in directly revealing the truth and solving problems.

\section{Emotional expression of epidemic documentary photography under visual communication}

Visual communication is to put people's feelings, psychology and emotions in the first place. Compared with art photography, most news photography works display disasters and diseases, which bring more shock, sadness and warning to people. Such works are more documentary. They mainly embody the special humanistic care for people, society and the age, and contains the deep beauty behind the images.

Photographic images are closely connected with the new technologies of modern media and are one of the important manifestation forms of information dissemination. As a new type of media, the emergence of photographic images adds a powerful force to the role of visual communication design, because the innovation of its image culture effectively mobilizes the application of visual language in visual communication design.

\subsection{Humanistic Feelings}

Beauty represents human's passion and pursuit for life, which is human nature. It exists in human activities and is the crystallization of the historical development of human activities. All the achievements of human civilization contain human's pursuit of beauty. It is this unique aesthetic effect that can truly shock our hearts.

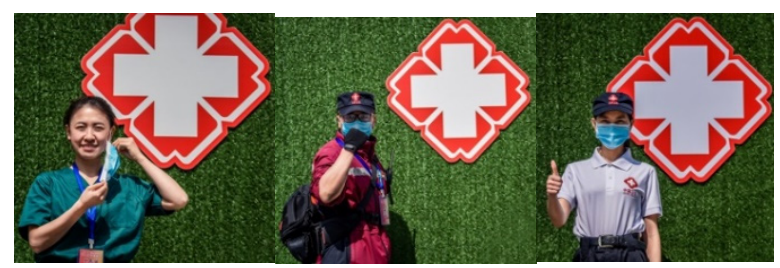

(Figure 3 The Angels' Face)

To enable the humanistic feelings of disaster documentary photography to play the greatest role in documentary photography, it is inseparable from the photographer's heart and also requires the photographer's full guidance in positive energy.

Take The Angels' Face as the example (Figure 3). On March 10, 2020, in Wuhan Hongshan Stadium, the last closed mobile cabin hospital, a group of photos of doctors and nurses who were taking off their masks was taken. These photos show people's sincere gratitude and great respect for their selfless contribution to fighting the pandemic.

\subsection{Emotional Experience}

Emotional resonance comes from documentary photography, and the power of emotions comes from the thoughts and feelings conveyed by images.

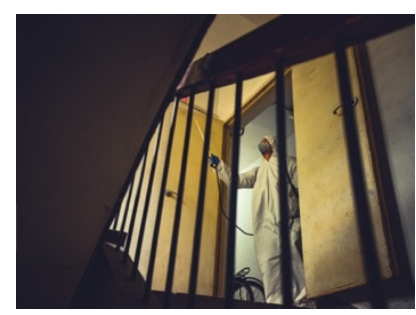

(Figure 4 Fighters of Disinfection and Sterilization)

The so-called "third eye" of news photography is to discover the beauty of emotional experience with visual impact. The power of emotions comes from the thoughts and emotions conveyed by images, which shocks the audience's spiritual and inner world. Photographer can not just stay on the superficial phenomena, but instead should observe carefully and understand the subtlest aspects. Photography works without emotions will never move people. Photographers always devote their real feelings and emotions to their creations. Only in this way can their works demonstrate real love. For example, in the work Fighters of Disinfection and Sterilization (Figure 4), a group of "disinfection and sterilization fighters" who were wearing protective suits shuttled from one community to another in order to disinfect and sterilize the residential buildings by using sprayers. They are the heroes of the city. What they firmly believe is that only when the communities are safe, every household will be safe. So they carefully complete every step of disinfection and sterilization in every single day to build a "defense line" for the city.

\subsection{Human and Society}

If you want to express a theme, you have to sublimate it to a higher level. Medical personnel from all over the country come together to support Hubei in fighting the virus. From their generous help, we can feel a noble and great spirit. The nobility in aesthetics evokes a magnificent and moving feeling and can sublimate the aesthetic enjoyment of the soul. In term of the form, it demonstrates rough, exciting, dynamic and majestic features, thus giving people a sense of shock. In the intensification of 
contradictions, it shows the strong character of heroes and the fundamental strength of the people.

Photography has its own rules, but there are no definite rules. To express "the glory of human nature" is also a form of visual communication. When talking about the relationship of images and texts in poster design, China's graphic designer Jin Daiqiang said, "there are various ways to use pictures in the design. And pictures can be used in whole or in parts."

After more than two months of fighting the virus, people in Hubei gave the doctors and nurses a send-off ceremony of the highest courtesy. During a short stay at the airport, people also took photos for each of them and these photos were made into posters so as to express people's gratitude for them. (Figure 5, Leaning in together and Proceeding to the Ligh).

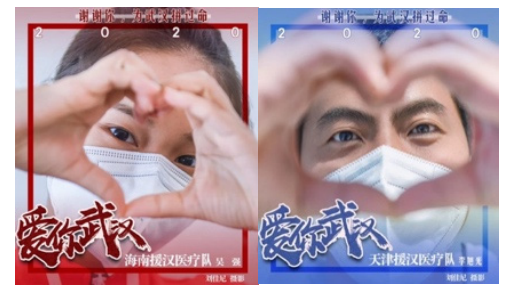

(Figure 5 Leaning in together and Proceeding to the Light)

\section{Influences of the Development of New Media on Visual Communication}

In today's world of diversified information and the age of picture explosion, with the rapid development of new media, visual communication has ushered in the era where tradition and modernity, history and future, the new and the old, reality and imagination coexist. Subtle changes are also taking place in the field of visual communication. People are passionate about innovation. The traditional media is trying to reform.

Nowadays everyone can become a documentary photographer. With a mobile phone, or a tablet computer in hands, using the Internet and various APPs, real-time uploading can be achieved. Although sometimes the photos uploaded may not be paid great attention to the composition, they still achieve authenticity and timeliness.

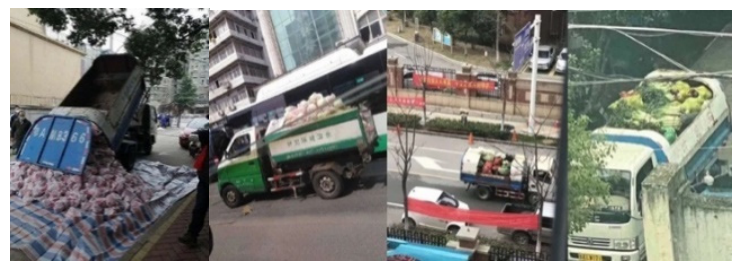

(Figure 6 from the Internet A Garbage Truck Carrying Relief Supplies)

An original video without any treatment became a hit during the outbreak. The video is about a quarrel between a man and several staff on the spot of raw pork distribution. It turned out that in a place call Gangdu Garden in Qingshan District of Wuhan City, someone should transport 1,000 pieces of affordable pork meat by sanitation truck. Worse still, it is the only sanitation truck used to transport food. It has almost become a common practice in certain areas to use sanitation trucks to transport food. Because of the timeliness and authenticity, this set of photos (Figure 6) can thus be quickly spread on the Internet, which allows people to truly know the inaction of some officials in face of the pandemic. This is also something that press photographers or media professionals cannot do. Because upon receiving the news, the "evidence" may have disappeared when people rush to the scene.

The influence of this set of photos has been greater than that of the shooting techniques. The authenticity is an important element that needs to be considered when today's new media try to achieve a successful combination of timeliness and aesthetic value.

\section{The Innovative Value of Photography to History under Visual Communication}

As what is often said, today's news will be tomorrow's history. So is it necessary to record disasters in the world through visual images? The answer is undoubtedly yes. It is precisely because of these image records that the future generations can see the suffering of their ancestors in the past.

At the graduation exhibition of Central Academy of Fine Arts for design students, a student used Lego bricks to reassemble the three photos of An Assassination in Turkey created by Burhan Ozbilici, the winner of World Press Photo, and then photographed them again to restore the scene at that time. While paying homage to the photographer, the student's work also enables people to remember history.

Since the principle of authenticity is the inherent requirement of the nature and function of news, it is insufficient to simply record the news in the face of news with disasters as themes. It is because recording disasters is not recording ordinary events. The records of disasters will not only be preserved as historical materials, but also provide a source for the future generation to understand the truth of disasters, as well as the authentic living style and skills of the previous generation. Through documentary photography, the authentic records of disasters should be responsible to the future generation, because the future generation can learn lessons from these authentic records and prevent the recurrence of similar tragedies.

\section{Conclusion}

In the long course of human society and history, images featured by it unique recordability are used to record human life and history, and to express ideas. News documentary photography enables people to better participate, perceive and experience the history.

Therefore, the value assignment and innovation of pictures can promote the solution of the problem. 


\section{Author}

*Jiani Liu, Hunan Normal University Fine Arts Academy, Changsha Hunan, China, e-mail: 546223424@qq.com

\section{References}

1. Zhang Wenhua. (2020) Shallow Analysis of the Authenticity and Artistry of Documentary Photography[J]. Literati and Artist of China, 195-196.

2. Fan Jiangfeng. (2020) Artistic and Subjective Expression of Images Featuring Epidemic Combating[N]. China Photography,002.

3. Zou Jiwen. (2011) Exploration and Analysis of the Value of Documentary Photography in Catastrophic Events_-Taking Wenchuan Earthquake for Example $[\mathrm{J}]$. Science \& Technology Information, $301+314$

4. Feng Xinyan. (2011) A Probe into the Expression of Content and Form Beauty of Photojournalism[J]. Journalism Lover,: 53-54.

5. Song Shu. (2013) News Photography: Formal Beauty and Documentary Beauty[J]. News Front, 89-90.

6. Lv Bu. (2015) Research on the Application of Formal Beauty in Photography[D]Hunan: Hunan Normal University.

7. Wang Yijin. (2018) Exploration and Analysis of the Value of the Authenticity of Documentary Photography[D]Shandong: Shandong University Of Arts. 